University Bremen. "For the family there were the summer holidays," he says.

At the European level he rose to be general director of the European Space Agency, just as big science was establishing itself. It became increasingly difficult to defend basic research against demands for immediate economic, military or societal returns. In Europe, in particular, a consensus needed to be found among the various nations because space research and other expensive projects exceeded the resources of even the large countries. Lüst remains convinced that Europe must develop its own technologies, saying, "You should give up the idea of ever being able to cooperate with the Americans in technological projects."

The final conversation in the book concerns science ethics. Here, Lüst seems to be curiously ambivalent about the tension between science and politics, the running theme of his career. He refers to the moral responsibility of politicians to listen to the opinion of scientists before making a decision, yet criticizes the same politicians for hiding their indecisiveness behind scientific expertise.

Nolte is a perceptive and well-prepared interviewer. His role in the discussions is to link Lüst's reminiscences to their historical context, and he succeeds well in doing so.
But the concept of the book is, at times, also its weakness. Nolte's title, The Science Maker, confines his questioning to Lüst's active professional roles rather than simply inviting the researcher to act as an educated witness to his times. This memoir fills a long-standing hole, placing the voice of a scientist among the many historical accounts of the twentieth century written by novelists and social scientists. More than that, it is an appeal from an exceptional scientist to his colleagues to accept responsibility in society.

Stefan Klein is a science writer based in Berlin. His latest book is Time: A User's Guide (US title The Secret Pulse of Time).

\title{
EXHIBITION
}

\section{Industrial paint's artistic legacy}

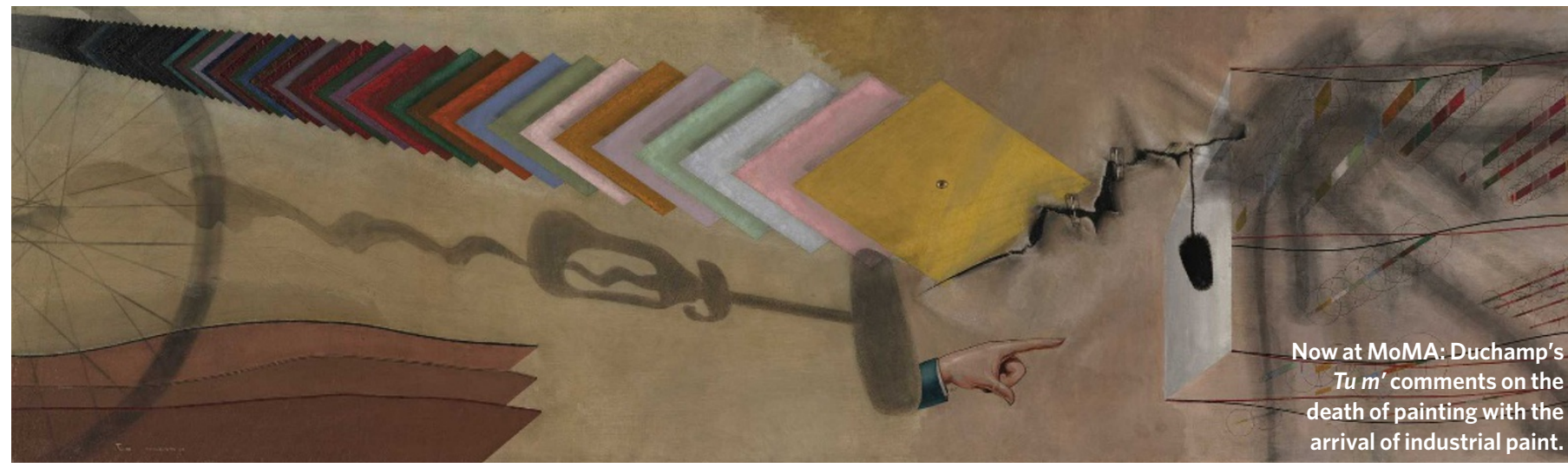

\section{Christopher Turner}

Since Isaac Newton, colour has often been equated with visual music. Color Chart: Reinventing Color, 1950 to Today, showing at New York's Museum of Modern Art (MoMA), takes a different view. It celebrates the influence of industrial, mass-produced and standardized hues on the art of the past 60 years. Astonishingly, it is the first exhibition devoted exclusively to colour in the museum's 79-year history.

Newton unified the art and science of colour by dividing the spectrum into seven colours - rather than eight - to make an analogy between the chromatic and musical scales. In his Opticks treatise of 1704, Newton pictured the primary colours and their complements as a circular diagram. Artists relied on this 'colour wheel' for the next two centuries to create visual harmonies in their paintings. In the synaesthetic abstractions of Vasily Kandinsky or the subtle vibrations of Josef Albers' geometric canvases, colours were given spiritual or affective attributes that built on Newton's scheme.

MoMA's exhibition takes its cue instead from a 1918 surrealist work by Marcel Duchamp enigmatically titled Tu m' (You (fillin-the-blank) $M e$ ). The three-metre-wide canvas was the artist's last painting; disillusioned with conventional art, he intended it as a comment on the end of painting itself. Juxtaposed with the ghostly grey shadows of Duchamp's famous 'ready-mades' - the urinal, the bicycle wheel and the bottle rack, which he exhibited to demonstrate that art could be found in utilitarian objects - is a cascade of lozenges of different colours that resemble samples from a commercial colour chart. In interpreting this canvas, the MoMA curators have made a case for industrial paint as a ready-made item in itself, and explore the revolutionary impact of Duchamp's legacy in the use of colour by contemporary artists.

Ready-mixed industrial paints became widely available for household use in the 1880 s, and were advertised with colour charts that altered Newton's circle by displaying hues in random rather than scientific order. In the 1950s, the more robust acrylic paint was invented. A fast-drying polymer, acrylic did not lend itself to the painterly mixing and layering of colours that oils allow. Consequently, the work of many of the 44 selected artists on show feature large monochromes or flat applications of colour. The artist's palette was jettisoned and colours applied directly to the canvas so as to, in Frank Stella's words, "keep the paint as good as it is in the can". Working in this way, as Andy Warhol affirmed, was essentially 'painting-by-numbers'.

In 1954, Yves Klein created a spoof brochure, designed to mimic a paint catalogue, to 'advertise' a series of non-existent canvases. This sample book was filled with large colour swatches with grandiose titles such as A Londres or A Paris (the latter is painted using the brilliant azure that Klein later patented as International Klein Blue). Twelve years later, Gerhard Richter enlarged the little sample cards that are available in hardware stores into panels forming a painting of 2.5-metre-high columns of vivid colour that is more than nine metres long.

Other works, including a series of collages by Ellsworth Kelly composed of squares of gum-backed paper and a spot painting by Damien Hirst, see colour applied in random, jarring combinations to queasy effect. Perhaps these works show us a portrait of our time. Kandinsky wrote that he saw the art of the past as if it were an orderly message from a vanished age. After experimenting with his own colour theory, and rejecting Newton's visual harmonies, he concluded that modernity was characterized instead by disorder: "Clashing discords, loss of equilibrium ... opposites and contradictions - this is our harmony."

Christopher Turner is a writer based in New York. 